\title{
DISSEMINAÇÃO DE INFORMAÇÃO EM SAÚDE E MÚSICA NO CONTEXTO HOSPITALAR PEDIÁTRICO
}

\author{
Maria Cristiane Barbosa Galvão \\ Universidade de São Paulo (USP) \\ mgalvao@usp.br \\ Paula Maria Pereira \\ Universidade de São Paulo (USP) \\ paulamp@usp.br \\ Fabio Carmona \\ Universidade de São Paulo (USP) \\ carmona@usp.br
}

Ivan Luiz Marques Ricarte

Universidade Estadual de Campinas (UNICAMP)

ricarte@unicamp.br

\begin{abstract}
Resumo
Estudos têm sido realizados para verificar formas de tornar a assistência pediátrica humanizada e inclusiva. Assim, teve-se por objetivo verificar se a disseminação de informações em saúde e de músicas na página de um hospital pediátrico, em uma rede social, promove algum tipo de reação ou envolvimento do público. O estudo, de caráter quantitativo, contemplou diferentes etapas do ciclo informacional, como: a seleção de informações em saúde e músicas; a produção de informações em saúde em linguagem simples; a disseminação de informações em saúde e músicas na página do hospital pediátrico. No período da intervenção, foram disseminadas 22 informações em saúde na página do hospital, que alcançaram um total de 19.156 pessoas, e 27 músicas que alcançaram um total de 17.914 pessoas. Embora informações em saúde e músicas promovam algum tipo de envolvimento, as informações em saúde são mais compartilhadas pelo público.
\end{abstract}

Palavras-chave: Informação em saúde. Música. Disseminação da informação. Hospital pediátrico.

\section{DISSEMINATION OF HEALTH INFORMATION AND MUSIC IN THE PEDIATRIC HOSPITAL CONTEXT}

\begin{abstract}
Studies have been conducted to verify ways to make pediatric care humane and inclusive. Thus, the objective was to verify if the dissemination of health information and music on the page of a pediatric hospital, in a social network, promotes reaction or public involvement. The quantitative study was conducted between May and June 2019, contemplating different stages of the informational cycle, such as: the selection of health information and music; the production of health information in simple language; the dissemination of health information and music on the pediatric hospital page. During the intervention period, 22 health information were disseminated on the hospital page, which reached a total of 19,156 people, and 27 songs that reached a total of 17,914 people. While health information and music promote some involvement, health information is more shared by the public.
\end{abstract}

Keywords: Health information. Music. Dissemination of information. Pediatric hospital.

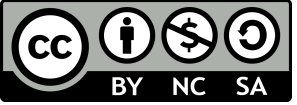




\section{INTRODUÇÃO}

A assistência em saúde de caráter terciário, também denominada de alta complexidade, abarca o acompanhamento de partos de alto risco, de condições oncológicas, cardiológicas, oftalmológicas, ortopédicas, neurológicas, psiquiátricas, transplantes, traumas e outras condições agudas e crônicas. Em muitos casos, essas condições demandam um acompanhamento de médio e longo prazo e podem demandar o emprego de tecnologias muito específicas e/ou de alto custo, como a quimioterapia, a radioterapia, a hemoterapia, a ressonância magnética, a prescrição e o uso de medicamentos de alto custo, órteses, próteses, procedimentos cirúrgicos e/ou múltiplas terapias. Dessa compreensão, deriva-se que os hospitais pediátricos de assistência terciária costumam acompanhar crianças e adolescentes desde o nascimento até os 18 anos ou mais de idade, em atendimento ambulatorial ou por meio da internação, fato que gera implicações cognitivas, emocionais e sociais para a crianças, seus pais e demais membros da família.

Dadas as características do paciente pediátrico no contexto hospitalar, muito estudos têm sido realizados para analisar formas para que a assistência pediátrica seja mais efetiva, humanizada e inclusiva. Everhart, Haskell e Khan (2019), por exemplo, afirmam que os pacientes e suas famílias devem estar e ser preparados para participar efetivamente de discussões e decisões de saúde. Assim, é imperativo que a comunicação com o paciente e sua família seja inclusiva, ou seja, empregue a linguagem apropriada, inclua informação por escrito e disponibilize informações relacionadas ao paciente por meio de tecnologias que os pais possam acessar com facilidade.

Kampouroglou et al. (2019) esclarecem que, no contexto hospitalar pediátrico, os pais possuem altos níveis de ansiedade, sobretudo quando as crianças e os adolescentes são agendados para a realização de uma cirurgia e que a ansiedade dos pais tem efeitos negativos, não apenas na criança e na família, mas também na consulta cirúrgica e no processo de consentimento informado. Os autores esclarecem ainda que os filhos de pais com conhecimento limitado em saúde tendem a ser levados mais frequentemente ao pronto-socorro, têm uma taxa mais alta de hospitalizações, possuem sintomas mais graves, bem como piores resultados de saúde. Finalmente, os autores concluem, após estudo com 664 pais, que os níveis de alfabetização em saúde dos pais e a necessidade de informação no cenário cirúrgico pediátrico não devem ser negligenciados durante as consultas pré-operatórias, pois os níveis de ansiedade dos pais parecem estar associados à necessidade de informação. 
Segundo Fong et al. (2018), a alfabetização em saúde é definida como a capacidade de obter, processar e compreender informações básicas de saúde e serviços necessários para tomar decisões apropriadas de saúde, sendo relacionada a comportamentos parentais positivos e a melhores resultados de saúde alcançados pela criança assistida. Após estudo com 253 pais de recém-nascidos, os autores concluíram que a alfabetização em saúde e a eficácia parental estão associadas bidirecionalmente, ou seja, o baixo nível de alfabetização em saúde pode levar os pais a terem baixa eficácia parental, de tal forma que pais menos capazes de obter, processar e entender informações e serviços básicos de saúde se sentem menos capazes de cuidar de seus filhos com sucesso. Por outro lado, a baixa eficácia parental pode levar os pais a ter baixo nível de alfabetização em saúde, pois ao terem menos confiança em suas habilidades parentais, tomam menos providências para desenvolver seus conhecimentos e habilidades em saúde.

De forma geral, os estudos citados sobre o contexto hospitalar pediátrico corroboram um consenso maior do campo da saúde, advindo desde ao menos os anos 90 do século 20 (SACKETT, 1997), de que o uso de informações em saúde, sobretudo aquelas com melhor nível de evidência científica, tem o potencial de melhorar a condição de saúde, o seguimento e a resiliência; de prevenir doenças ou seu agravamento; de evitar tratamentos, procedimentos diagnósticos, intervenções preventivas ou encaminhamentos inapropriados ou desnecessários; de reduzir preocupações sobre tratamentos, procedimentos diagnósticos ou intervenções preventivas; e de aumentar o conhecimento de profissionais, pacientes ou de seus familiares sobre condições de saúde. Disso resulta a importância de se pensar em formas de disseminação da informação em saúde em linguagem simples para a população leiga.

No que se refere às necessidades emocionais de pacientes pediátricos e suas famílias no contexto hospitalar, Logan et al. (2019) realizaram um estudo empregando robôs sociais com 54 crianças de 3 a 10 anos de idade. Tais robôs eram, basicamente, ursinhos de pelúcia interativos. A intervenção tecnológica foi bem recebida e pareceu viável, com 93\% dos inscritos completando o estudo. As crianças expostas aos robôs sociais expressaram mais afeto em relação àquelas que receberam um urso de pelúcia convencional, além de maiores níveis de alegria e amabilidade. Como conclusão os autores observaram a importância do uso de novas tecnologias no contexto pediátrico hospitalar.

Além de informações e de novas tecnologias digitais, alguns estudos têm considerado os efeitos da música no contexto hospitalar pediátrico. Preti e Welch (2011) observaram, por meio de estudo envolvendo 162 crianças, 146 cuidadores e 9 músicos, que a intervenção musical ajuda as crianças e suas famílias a diminuírem as tensões relacionadas à doença, deixando o ambiente hospitalar menos triste e com maior interação nos momentos de dor. 
Assim, entendem que a música é uma ferramenta poderosa para aliviar aspectos negativos da hospitalização e para nutrir um senso de bem-estar individual, coletivo e institucional. Além disso, verificaram que a música ao vivo oferece à criança e aos seus cuidadores uma oportunidade de se distraírem da ansiedade e do estresse provocados pela hospitalização, bem como do sofrimento relacionado às suas condições físicas.

Shuman et al. (2016), partindo do entendimento de que a musicoterapia pode ser uma poderosa ferramenta para a comunicação no contexto hospitalar pediátrico, realizaram um estudo envolvendo 352 participantes entre 12 e 21 anos de idade, que completaram 596 registros de humor entre agosto de 2010 e março de 2013. O estudo utilizou músicas gravadas, fones de ouvido e aplicativos disponíveis na Internet para reproduzir qualquer música solicitada pelos pacientes e concluiu que ouvir músicas pode alterar o humor dos pacientes, de diferentes sexos, idades e diagnósticos. Os autores concluíram o estudo afirmando que esses resultados iniciais podem apoiar novas pesquisas sobre os benefícios da musicoterapia para adolescentes que sofrem de transtornos psiquiátricos.

Em harmonia com os estudos anteriores, Due e Ghetti (2018) realizaram um estudo envolvendo a musicoterapia com crianças hospitalizadas, de setembro de 2016 a janeiro de 2017. Os autores concluíram que a musicoterapia, com a colaboração das enfermeiras e a presença dos musicoterapeutas, pode ser implementada como um complemento para ativação e educação de crianças hospitalizadas, e é recomendada como parte do tratamento holístico dos sintomas em cuidados paliativos. Assim, deve ser desenvolvida como parte integrada e natural da assistência, do tratamento e do acompanhamento para crianças e jovens nos serviços de saúde.

Os estudos elencados delineiam importantes caminhos para que a assistência hospitalar pediátrica seja mais humana e efetiva. Salientam a necessidade de melhor informar e capacitar os atores envolvidos na assistência da criança e do adolescente, bem como a necessidade de tornar o ambiente mais acolhedor para esse público, seja por meio de novas tecnologias, seja por meio da música. Dessa maneira, este estudo de intervenção de caráter exploratório teve por objetivo verificar se a disseminação de informações em saúde e de músicas na página de um hospital pediátrico, em uma rede social, promove algum tipo de reação ou envolvimento dessa população. 


\section{METODOLOGIA}

O projeto envolveu as diferentes etapas do ciclo informacional, incluindo a seleção, produção de síntese e disseminação de informações em saúde em linguagem simples como foco na população leiga e a seleção e disseminação de músicas.

Para a seleção, produção de síntese informacional e disseminação de informações em saúde consideraram-se temáticas variadas que poderiam ser de interesse dos pais ou responsáveis pelos pacientes atendidos no hospital pediátrico, incluindo-se temas como: violência; estágios da adolescência; gravidez na adolescência; sangramento no nariz; anticoncepcionais; hipertricose; herpes congênita; acidentes domésticos; fraturas; pneumonia; edema pulmonar; inchaço corporal; meningite; e rinite alérgica.

Para a produção de síntese informacional sobre as temáticas elencadas, a equipe de pesquisa e colaboradores buscou evidências científicas em bases de evidência e produziu um resumo, em linguagem simples, buscando uma redação: clara; concisa; bem organizada; empregando voz ativa; frases curtas; palavras comuns e cotidianas; e recursos de design fáceis de ler (UNITED STATES, 2019). Cada síntese informacional foi constituída por: uma questão clínica; uma resposta clínica curta de até 160 caracteres; resposta clínica longa de até 500 palavras. Para cada conteúdo informacional foi selecionada e adicionada uma foto contendo um ou vários humanos de diferentes etnias, mas, sobretudo, crianças, jovens do sexo feminino e masculino, e casais. A equipe de pesquisa analisou e revisou o conteúdo informacional e a foto antes de sua publicação.

Para a seleção das músicas, a equipe de pesquisa considerou Preti e Welch (2011) que, ao realizarem um estudo com o uso de música em um hospital pediátrico na Itália, estabeleceram algumas tipologias de músicas a serem divulgadas para crianças no contexto hospitalar, como: músicas instrumentais, músicas de desenhos animados, músicas folclóricas, músicas populares e músicas relaxantes. Considerando os resultados positivos obtidos por Preti e Welch (2011) e o público-alvo do hospital pediátrico em questão, situado no Estado de São Paulo, Brasil, foram selecionadas músicas populares brasileiras, músicas do folclore brasileiro, músicas instrumentais potencialmente conhecidas por brasileiros, músicas de desenhos animados e músicas regionais brasileiras.

Tanto as sínteses informacionais produzidas sobre saúde quanto as músicas selecionadas foram disseminadas pela equipe de pesquisa na página de uma rede social de um hospital pediátrico, durante o período de 16 de maio de 2019 a 26 de junho de 2019, de segunda a sextafeira, excetuando-se feriados. Esteticamente, todos os conteúdos publicados apresentavam a 
mesma estrutura visual e eram posicionados na página em ordem cronológica, com a publicação mais recente no início da página, a fim de que todos os conteúdos tivessem a mesma oportunidade de serem vistos e compartilhados, conforme recomendam Kümpel, Karnowski e Keyling (2015).

No processo de disseminação, optou-se por uma abordagem de acesso orgânico, ou seja, não se financiou ou fomentou os conteúdos publicados na página do hospital. Os dados quantitativos resultantes da disseminação das informações em saúde e das músicas na página do hospital pediátrico foram coletados 60 dias após o final da intervenção e foram analisados por meio de estatística descritiva. Na dimensão ética, considerou-se que o estudo se enquadra na pesquisa quantitativa de dados públicos coletados em redes sociais, sem a identificação de participantes, estando essa modalidade de pesquisa acolhida pela Resolução no 510 (BRASIL, 2016).

\section{RESULTADOS}

Atualmente, a página do hospital pediátrico conta com 5.777 seguidores, dos quais $89 \%$ são mulheres e $70 \%$ possuem entre 25 e 44 anos. Dessa forma, o público principal da página é de mulheres adultas. Em relação à origem geográfica dos seguidores, a maioria deles é do Estado de São Paulo, Brasil, e são falantes da língua portuguesa.

No período da intervenção, foram publicadas 22 informações em saúde e 27 músicas, conforme os conteúdos apresentados nos Quadros 1 e 2. Os conteúdos sobre saúde tiveram o alcance total de 19.120 pessoas e as músicas tiveram o alcance total de 17.941 pessoas, perfazendo o total global de 37061 pessoas alcançadas, conforme apresentado no Gráfico 1. Considerando a quantidade de informação em saúde e a quantidade de músicas disseminadas, observou-se que, em média, os conteúdos sobre saúde tiveram alcance $31 \%$ maior.

Em relação à informação em saúde, o alcance maior esteve relacionado às seguintes questões: 1) Qual a causa do sangramento do nariz?, com 1.763 pessoas alcançadas; 2) O que é rinite alérgica?, com 1.763; 3) O que é meningite?, com 1.266; 4) Como tratar sangramentos no nariz?, com 1.242; e 5) Quais são os sinais de estupro contra mulheres?, com 1.189 pessoas alcançadas. Já os conteúdos que alcançaram menos pessoas foram: 1) Qual o tratamento para o excesso de pelos no corpo?, com 456 pessoas alcançadas; 2) Qual é o tratamento para inchaço?, com 480; 3) Como identificar se um nariz está quebrado?, com 525; 4) O que é herpes genital?, com 539; e 5) Como tratar um nariz quebrado?, com 551 pessoas alcançadas. 
De forma geral, observou-se que as informações sobre condições de saúde que afetam um maior número de pessoas tiveram maior alcance. É importante ressaltar que o estudo foi realizado entre o final do outono e início do inverno, onde algumas dessas condições de saúde são mais frequentes. Além disso, durante o período da intervenção, foram registrados casos de meningite na região do estudo.

Em relação à música, o alcance maior esteve relacionado às seguintes obras: 1) Jennifer (Gabriel Diniz), com 1.550 pessoas alcançadas; 2) Tocando em frente (Almir Sater), com 1.303; 3) Stand by me (Ben E. King), com 1.014; 4) O sol (Jota Quest e Milton Nascimento), com 847; e 5) La belle de Jour (Alceu Valença), com 837. Já as músicas que alcançaram menos pessoas foram: 1) História de uma gata (Os Saltimbancos), com 296 pessoas alcançadas; 2) O circo (Nara Leão), com 328; 3) Cidade Maravilhosa (Brazilian Flash Mob), com 350 pessoas alcançadas; 4) Escravos de Jó (Galinha Pintadinha), com 383; e 5) Tropicana (Alceu Valença), com 391. De forma geral, as músicas para crianças alcançaram menos pessoas que as músicas populares para adultos. Talvez, porque, embora o hospital seja pediátrico, o público que acessa a página da instituição é adulto.

Quadro 1 - Informações em saúde disseminadas na página do hospital pediátrico

\begin{tabular}{|l|l|}
\hline Informação em saúde & Data \\
\hline Qual a importância de se observar um inchaço no corpo? & $16 / 05 / 2019$ \\
\hline O que é meningite? & $20 / 05 / 2019$ \\
\hline Qual é o tratamento para a meningite? & $21 / 05 / 2019$ \\
\hline Qual é o tratamento para inchaço? & $22 / 05 / 2019$ \\
\hline O que é edema pulmonar? & $23 / 05 / 2019$ \\
\hline Qual é o tratamento para edema pulmonar? & $24 / 05 / 2019$ \\
\hline Como tratar a pneumonia? & $27 / 05 / 2019$ \\
\hline Como identificar se um nariz está quebrado? & $28 / 05 / 2019$ \\
\hline Como tratar um nariz quebrado? & $29 / 05 / 2019$ \\
\hline Por que algumas pessoas possuem pelos em excesso? & $30 / 05 / 2019$ \\
\hline Qual o tratamento para o excesso de pelos no corpo? & $03 / 06 / 2019$ \\
\hline O que é herpes genital? & $04 / 06 / 2019$ \\
\hline Como prevenir a transmissão da herpes genital? & $05 / 06 / 2019$ \\
\hline Qual a causa do sangramento do nariz? & $06 / 06 / 2019$ \\
\hline Como prevenir os sangramentos no nariz? & $07 / 06 / 2019$ \\
\hline Como evitar a gravidez? & $10 / 06 / 2019$ \\
\hline Como tratar sangramentos no nariz? & $11 / 06 / 2019$ \\
\hline Quais são os estágios da adolescência? & $12 / 06 / 2019$ \\
\hline Quais são os sinais de estupro contra mulheres? & $13 / 06 / 2019$ \\
\hline O que é rinite alérgica? & $17 / 06 / 2019$ \\
\hline Todas as crianças têm muitas infecções? & $18 / 06 / 2019$ \\
\hline Como prevenir maus tratos contra crianças? & $20 / 06 / 2019$ \\
\hline
\end{tabular}

Fonte: Elaboração própria 
Quadro 2 - Músicas disseminadas na página do hospital pediátrico

\begin{tabular}{|l|l|}
\hline Música & Data \\
\hline Aquarela (Toquinho) & $17 / 05 / 2019$ \\
\hline A linda rosa juvenil (Caseirices Kids) & $20 / 05 / 2019$ \\
\hline Escravos de Jó (Galinha Pintadinha) & $21 / 05 / 2019$ \\
\hline O circo (Nara Leão) & $22 / 05 / 2019$ \\
\hline O caderno (Chico Buarque) & $23 / 05 / 2019$ \\
\hline Samba de Arerê (Brasil Samba Congress 2019) & $24 / 05 / 2019$ \\
\hline Baile dos passarinhos (A Turma Do Balão Mágico) & $27 / 05 / 2019$ \\
\hline Jennifer (Gabriel Diniz) & $28 / 05 / 2019$ \\
\hline Cidade Maravilhosa (Brazilian Flash Mob) & $29 / 05 / 2019$ \\
\hline Can you feel the love tonight (Santiago Instrumental) & $30 / 05 / 2019$ \\
\hline La belle de Jour (Alceu Valença) & $03 / 06 / 2019$ \\
\hline Exagerado (Cazuza) & $04 / 06 / 2019$ \\
\hline O sol (Jota Quest e Milton Nascimento) & $05 / 06 / 2019$ \\
\hline História de uma gata (Os Saltimbancos) & $06 / 06 / 2019$ \\
\hline Shallow (Lady Gaga) & $07 / 06 / 2019$ \\
\hline Tropicana (Alceu Valença) & $10 / 06 / 2019$ \\
\hline Stand by me (Ben E. King) & $11 / 06 / 2019$ \\
\hline Love story (2Cellos) & $12 / 06 / 2019$ \\
\hline Girls like you (Maroon 5) & $13 / 06 / 2019$ \\
\hline Boi da cara preta (Caseirices Kids) & $14 / 06 / 2019$ \\
\hline O pato (MPB4) & $17 / 06 / 2019$ \\
\hline A bailarina (Lucinha Lins) & $18 / 06 / 2019$ \\
\hline Mas que nada (Sergio Mendes and Brazil 66) & $19 / 06 / 2019$ \\
\hline A bicicleta (Toquinho) & $20 / 06 / 2019$ \\
\hline O elefante (Robertinho de Recife) & $21 / 06 / 2019$ \\
\hline Frevo mulher (Zé Ramalho) & $25 / 06 / 2019$ \\
\hline Tocando em frente (Almir Sater) & $26 / 06 / 2019$ \\
\hline & \\
\hline & \\
\hline
\end{tabular}

Fonte: Elaboração própria

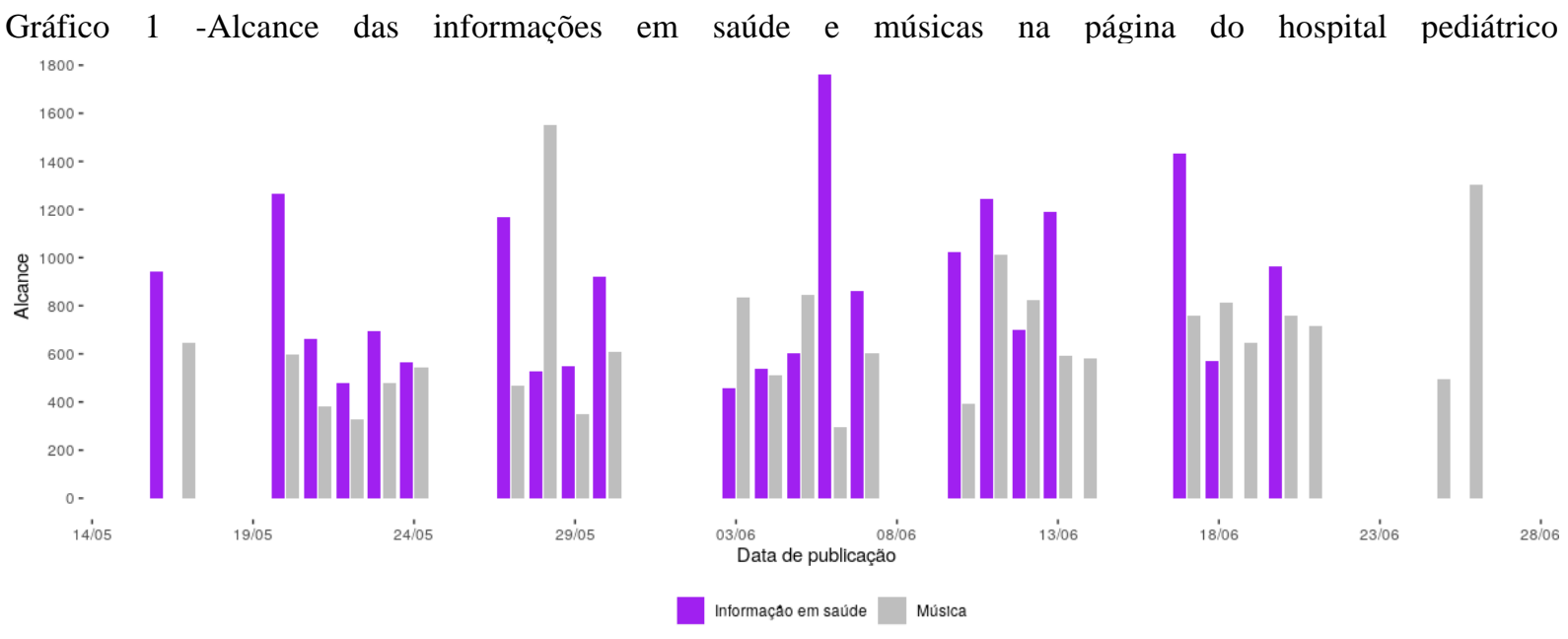

Fonte: Elaboração própria

O Gráfico 2 apresenta os envolvimentos obtidos com as informações e músicas disseminadas. Incluíram-se no envolvimento curtidas, comentários, compartilhamentos e 
demais interações. Assim, observou-se que os 22 conteúdos informacionais em saúde disseminados tiveram o total de 787 envolvimentos e as 27 músicas tiveram 667 envolvimentos, perfazendo o total global de 1.454 envolvimentos. Os conteúdos com maior e menor envolvimento foram também os mesmos que tiveram maior e menor alcance. Porém, considerando a quantidade de 22 informações em saúde e 27 músicas, o envolvimento médio do público com as informações em saúde foi $45 \%$ maior que o envolvimento com as músicas, ressaltando que o público da página do hospital pediátrico parece possuir um interesse mais diferenciado por informação em saúde que por música.

Gráfico 2 - Envolvimento obtido pelas informações em saúde e músicas disseminadas na página do hospital pediátrico

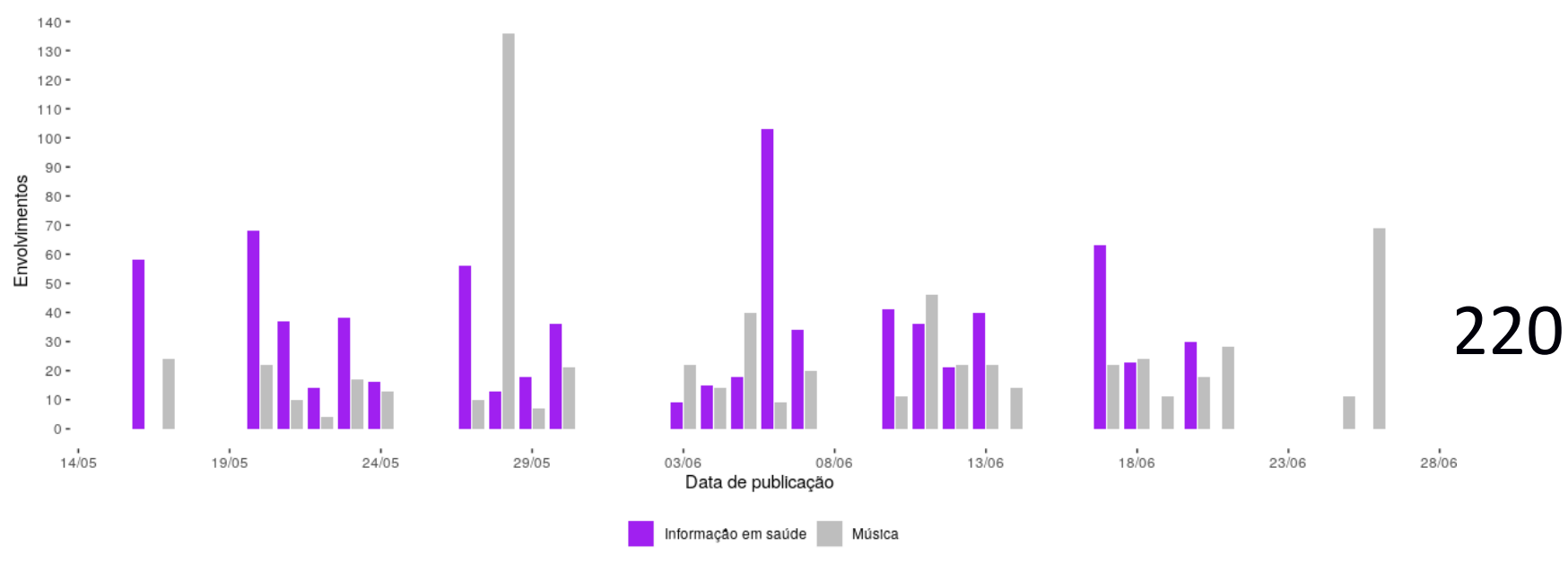

Fonte: Elaboração própria

Cabe destacar que a música com maior envolvimento (136) foi a obra Jennifer, publicada no dia do falecimento do cantor Gabriel Diniz, indicando uma reação natural do público diante de uma fatalidade.

Em relação aos compartilhamentos, observou-se que as informações em saúde tiveram 98 compartilhamentos e as músicas tiveram 23 compartilhamentos, perfazendo o total global de 121 compartilhamentos, conforme apresentado no Gráfico 3. Comparativamente, o compartilhamento médio de informações em saúde foi $423 \%$ maior que o compartilhamento de músicas, indicando que o público tem não apenas interesse nesse tipo de conteúdo informacional, como também tem interesse em repassá-lo em suas redes sociais. Faz-se notar que a música mais compartilhada foi Tocando em frente (Almir Sater), com 8 compartilhamentos. Os demais conteúdos tiveram a quantidade de compartilhamento similar ao alcance e ao envolvimento. 
Gráfico 3 - Compartilhamentos das informações em saúde e músicas disseminadas na página do hospital pediátrico

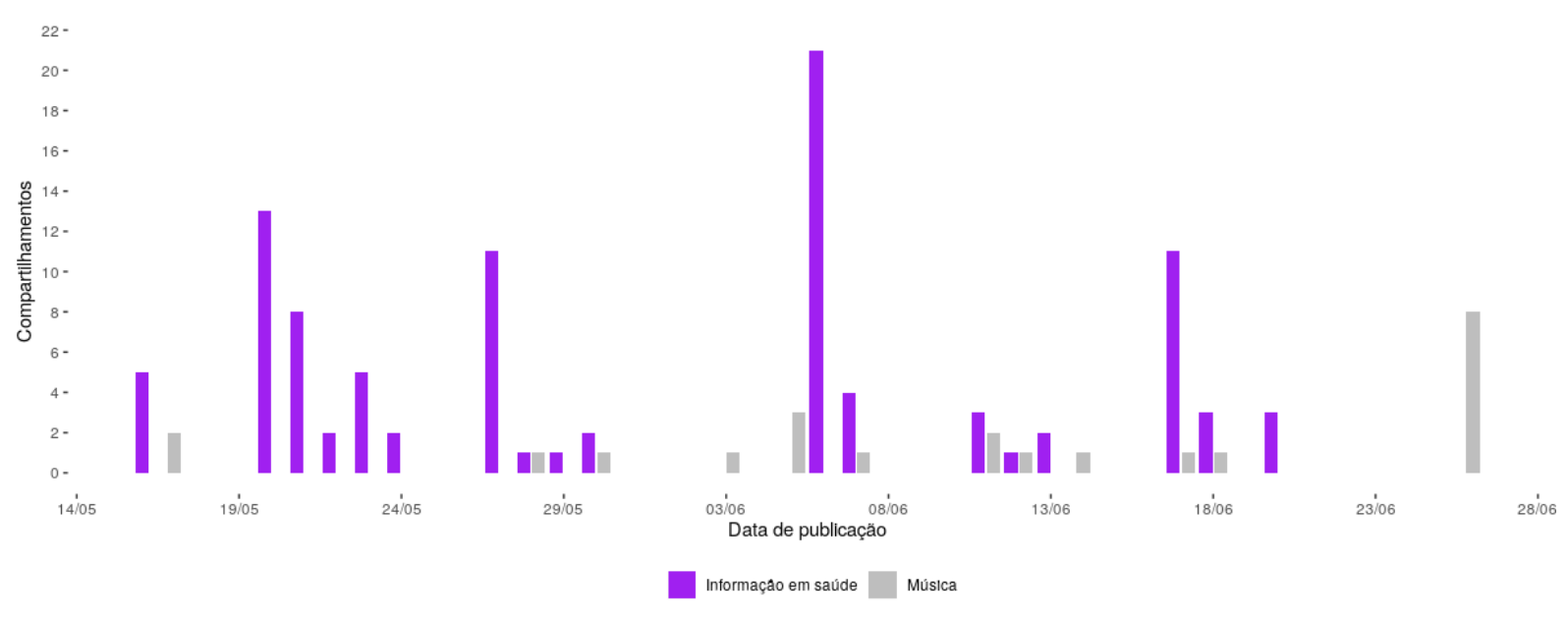

Fonte: Elaboração própria

Na comparação direta entre informação em saúde e música, percebe-se que o público tem alguma preferência à informação em saúde, como representado no Gráfico 4. Nesse gráfico, que compara a distribuição normalizada de alcance, compartilhamento, curtidas e envolvimento das informações em saúde com a mesma distribuição para as músicas, percebe-se que, para todas essas métricas, a média obtida por informações em saúde é superior à obtida por músicas.

Gráfico 4 - Comparação dos impactos das informações em saúde e músicas disseminadas na página do hospital pediátrico

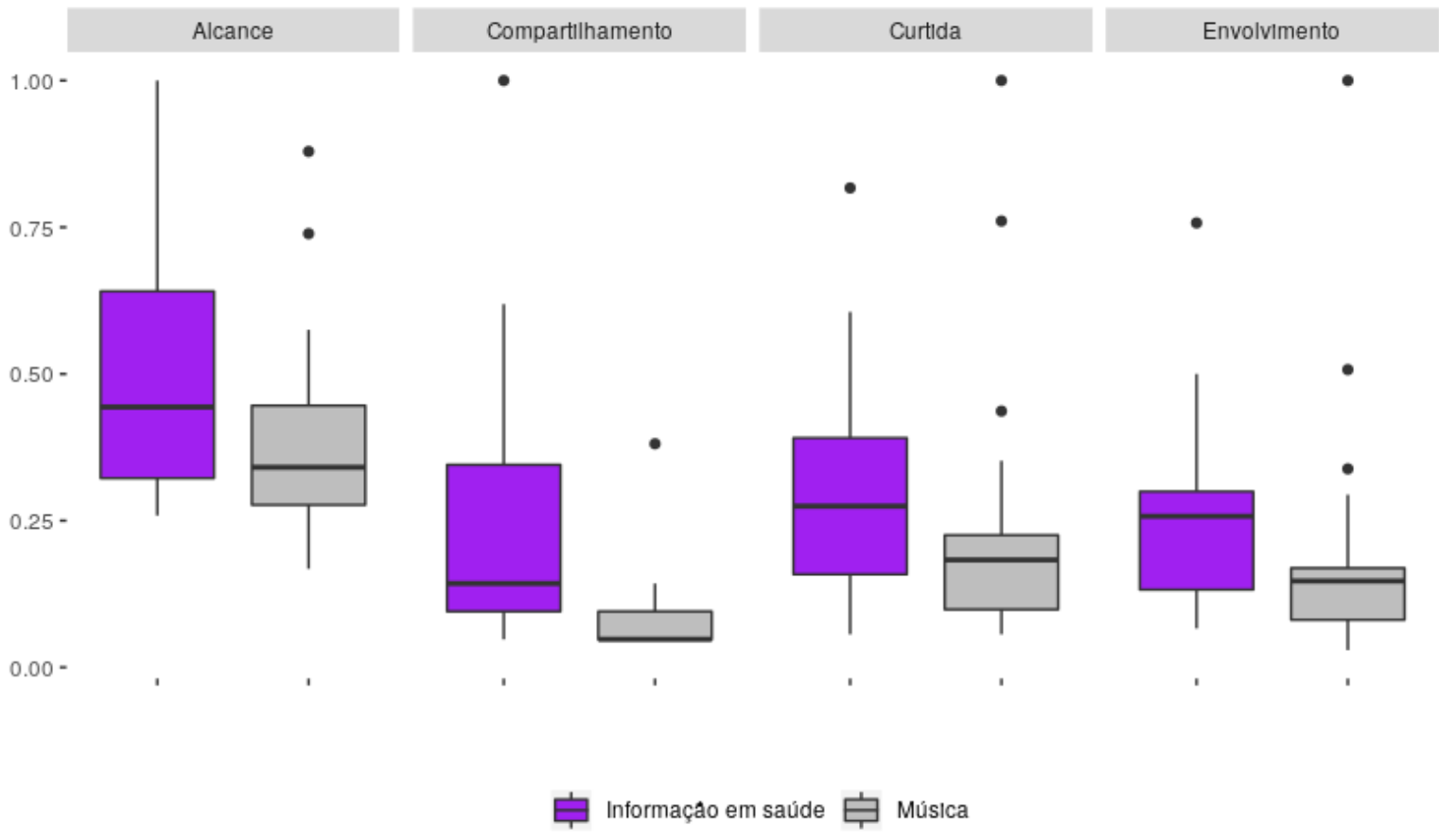

Fonte: Elaboração própria

P2P \& INOVAÇÃO, Rio de Janeiro, v. 6 n. 1, Ed. Especial, p.212-223, 2019. 


\section{CONCLUSÃO}

Observou-se que tanto a disseminação de informações em saúde como a disseminação de músicas na página de um hospital pediátrico, em uma rede social, promove algum tipo de reação ou envolvimento desta população. Contudo, o alcance e o compartilhamento de informações em saúde é, respectivamente, $31 \%$ e $423 \%$ maior que o de músicas.

Sobre o alcance, imagina-se que esses dados podem estar associados ao fato de o público da página ter, potencialmente, um familiar (criança ou adolescente) que é paciente no hospital pediátrico terciário, o que lhes demanda maior necessidade informacional para manejar seu cotidiano.

Sobre o compartilhamento, notou-se que o público da página repassa o conteúdo sobre saúde de modo direto a conhecidos, por meio da marcação de nomes próprios nos comentários de cada publicação, provavelmente, por ter reconhecido na informação a condição vivida por essas outras pessoas ou por quem elas são responsáveis. Além disso, em algumas situações, o público compartilha a informação em saúde com toda a rede social, pois pode ter reconhecido na publicação um conteúdo novo que merece ser passado adiante. Neste caso, o compartilhamento pode derivar de alguma dimensão altruísta do público.

Há que se considerar ainda que a música, ao ser menos compartilhada, pode estar atendendo a dimensão mais espiritual, emocional e individual do público. Nesse sentido, cabe reiterar que a música mais compartilhada pelo público foi Tocando em frente, que traz uma mensagem de esperança e resiliência, perante as dificuldades da vida, conforme dizem seus versos:

\section{"Ando devagar \\ Porque já tive pressa \\ E levo esse sorriso}

Porque já chorei demais (...)

(Tocando em frente, Almir Sater)

Finalmente, este estudo pode verificar que envolvimento e o compartilhamento de conteúdo informacional, na página de um hospital pediátrico, deriva de uma ação reflexiva e não aleatória do público. Todavia, recomenda-se a produção de novos estudos a fim de se conhecer mais profundamente quais são os benefícios que as informações em saúde e outros conteúdos informacionais como a música podem gerar nos diferentes públicos que frequentam unidades de saúde. 


\section{REFERENCIAS}

BRASIL. Ministério da Saúde. Conselho Nacional de Saúde. Resolução n. 510, de 7 de abril de 2016.

DUE, F. B.; GHETTI, C. M. Implementation of music therapy at a Norwegian children's hospital: a focused ethnographic study. Voices: A World Forum for Music Therapy, v. 18, n. 2, p. 1-21, 2018.

EVERHART, J. L.; HASKELL, H.; KHAN, A. Patient and family centered care: leveraging best practices to improve the care of hospitalized children. Pediatric Clinics of North America, v. 66, n. 4, p. 775-789, 2019.

FONG, H. F. et al. Association between health literacy and parental self-efficacy among parents of newborn children. Journal of Pediatrics, v. 202, n. Nov., p. 265-271, 2018.

KAMPOUROGLOU, G. et al. Parental anxiety in pediatric surgery consultations: the role of health literacy and need for information. Journal of Pediatric Surgery, s.v., s.n., p. 1-7, 2019.

KÜMPEL, A.S.; KARNOWSKI, V.; KEYLING, T. News sharing in social media: a review of current research on news sharing users, content, and networks. Social Media + Society, v. Jul-Dec, p. 1-14, 2015.

LOGAN, D. E. et al. Social robots for hospitalized children. Pediatrics, v. 144, n. 1, 2019.

PRETI, C.; WELCH, G. F. Music in a hospital: the impact of a live music program on pediatric patients and their caregivers. Music \& Medicine, v. 3, n. 4, p. 213-223, 2011.

SACKETT, David L. Evidence-based medicine. Seminars in Perinatology, v. 21, n. 1, p. 3$5,1997$.

SHUMAN, J. et al. Group music therapy impacts mood states of adolescents in a psychiatric hospital setting. Arts in Psychotherapy, v. 49, p. 50-56, 2016.

UNITED STATES. Plain language definition. Disponível em: https://www.plainlanguage. gov/about/definitions/. Acesso em: 25 ago. 2019. 